\title{
O EFEITO DE ANIMACIDADE NA PRODUÇÃO ELICIADA DE OBJETOS CORREFERENCIAIS NO PORTUGUÊS BRASILEIRO
}

\author{
Rosane LIRA ID $\boldsymbol{X}$ \\ Pontifícia Universidade Católica do Rio de Janeiro (PUC-Rio) \\ Letícia M. S. CORRÊA ID \\ Pontifícia Universidade Católica do Rio de Janeiro (PUC-Rio)
}

\section{ఠ}

OPEN ACCESS

EDITADO POR

- Miguel Oliveira, Jr. (UFAL)

- René Almeida (UFS)

REVISADO POR

- Mailce Mota (UFSC)

- José Ferrari Neto (UFPB)

SOBRE OS AUTORES

- Rosane Lira

Conceptualização, Escrita -

Rascunho Original, Escrita - Análise.

- Letícia M. S. Corrêa

Conceptualização, Escrita - Análise e Edição.

DATAS

- Recebido: 03/02/2020

- Aceito: 16/06/2020

- Publicado: 21/12/2020

\section{COMO CITAR}

LIRA, Rosane; CORREAA, Letícia M. S. (2020). O efeito de animacidade na produção eliciada de objetos correferenciais no português brasileiro. Cadernos de Linguística, v. 1, n. 2, p. 01-21.
RESUMO

O objetivo desse estudo é verificar em que medida o traço de animacidade do antecedente é um fator que contribui na seleção de uma determinada forma para a realização do objeto direto correferencial no curso da aquisição do português brasileiro (PB). Adicionalmente, verifica-se em que medida restrições ao objeto nulo em contexto de ilha sintática, que se aplicam ao português europeu (PE), podem interferir nesse efeito, levando em conta a produção oral e escrita de adultos. Duas tarefas de produção eliciada foram utilizadas: resposta a perguntas-QU e cloze. Os resultados apontam para a relevância de animacidade, independentemente de idade, afetando não só o pronome tônico e o objeto nulo, como o DP completo. Restrições sintáticas ao objeto nulo não se impõem, no geral, no PB, embora possa haver resquícios dessas restrições em decorrência de escolarização.

\section{ABSTRACT}

The aim of this paper is to verify the effect of animacy in the encoding of a correferential direct object in the acquisition of Brazilian Portuguese (BP). Additionally, syntactic restrictions on the occurrence of the null object in island contexts, which apply to European Portuguese (EP), are 
investigated, taking into account adults' oral and written production data.

Two elicited production tasks are used: a WH-question and a cloze task. The results support the relevant role of animacy regardless of age, not only in the production of pronominal forms but also in the production of full DPs. Syntactic restrictions on the null object do not generally apply in $\mathrm{PB}$, though traces of those constraints may still prevail as a consequence of schooling.

\section{PALAVRAS-CHAVE}

Correferência; Objeto Nulo; Produção da Linguagem; Animacidade; Português Brasileiro.

\section{KEYWORDS}

Coreference; Null Object; Language Production; Animacy;

Brazilian Portuguese. 


\section{INTRODUÇÃO}

Este estudo focaliza o modo como a correferência se estabelece em posição de objeto direto de $3^{\mathrm{a}}$ pessoa, na produção da fala por crianças falantes nativas de Português Brasileiro (PB).

O objeto correferencial $(\mathrm{OC})$ de $3^{\mathrm{a}}$ pessoa pode se realizar por meio de um DP definido completo e de formas pronominais - o pronome tônico, que, no PB, se sobrepõe ao clítico acusativo, predominante no português europeu (PE). No PB, o clítico acusativo é pouco produtivo, com uso praticamente restrito à língua escrita ou à fala por esta influenciada, em registros formais ou semi-formais (CYRINO, 1994, 2006; DUARTE, 2001; NUNES, 1996; NUNES, 2015; OLIVEIRA, 2005; PAGOTTO, 1996; TARALLO, 1983). O PB, tal como o PE, admite ainda o objeto nulo, embora sua natureza possa ser distinta nessas duas variedades (CYRINO, 19941, 2006; COSTA; GROLLA, 2017; COSTA; LOBO, 2011, 2016).

A teoria linguística apresenta restrições ao antecedente passível de ser recuperado por um OC: este não pode ser, a princípio, correferencial ao sujeito da oração que o contém (Princípio B da Teoria da Ligação, CHOMSKY, 1981). Contudo, a seleção de uma ou outra forma de recuperação de um antecedente legítimo irá sofrer restrições pertinentes a suas propriedades (semânticas, sintáticas ou discursivas), assim como das propriedades da forma anafórica em questão. No caso do objeto nulo, por exemplo, pode haver restrições sintáticas à sua realização, dependendo de sua natureza: se variável ligada, forma pronominal ou elíptica (RAPOSO, 1986, dentre outros).

Este estudo tem como objetivo investigar em que medida o traço semântico animacidade afeta o modo como o OC é codificado, se há diferença no modo como tal codificação é feita, ao longo do desenvolvimento, e em que medida o contexto sintático afeta a opção pelo objeto nulo, o que pode ser informativo quanto ao seu status na língua.

Dados da aquisição da linguagem, com base na fala espontânea de crianças têm sugerido ser animacidade um fator relevante na codificação do OC por meio de formas tônicas ou nulas em PB (LOPES, 2003; LOPES; QUADROS, 2005; CASAGRANDE, 2006; CASAGRANDE; ROSSI, 2015). No PE, sabe-se que o objeto nulo ocorre em contextos específicos e que as crianças pequenas omitem clíticos, mas não se sabe em que medida animacidade é um fator relevante nessa codificação (COSTA; LOBO, 2005, 2006, 2011).

1 Em Cyrino (1994), na seção 5.1, a autora contrapõe exemplos seus aos de Raposo (1996); tratando o objeto nulo em PE da mesma forma que trata o objeto nulo no PB, a saber, como uma elipse de DP. Cyrino aponta que em ambas as variedades do português, os objetos nulos podem ocorrer em ilhas; contudo, no PE, para que isso ocorra, algumas condições são necessárias. Contudo, os exemplos de retomada correferencial citados nesse ponto do trabalho nem sempre parecem preencher as condições necessárias a uma elipse de DP, como, por exemplo, a leitura ambígua (sloppy) do referente. Os resultados experimentais de um estudo mais aprofundado do tema estão em andamento. 
O presente estudo aborda as possíveis realizações do OC em PB no contexto de uma investigação psicolinguística. Busca verificar a hipótese de que animacidade é um fator relevante para a distinção entre tônicos e nulos no PB no curso da aquisição da língua, fazendo uso de metodologia experimental - produção eliciada de OCs. Busca ainda, por meio dessa metodologia, verificar em que medida restrições sintáticas ao uso do objeto nulo, observadas em PE, podem se impor ao falante de PB. Há evidências de que adultos falantes do PE preferem o clítico ao objeto nulo em determinados contextos de ilha sintática, ainda que crianças façam maior uso do objeto nulo nesses contextos (COSTA; LOBO, $2005,2006,2011)$. Assim sendo, os dados de crianças/adolescentes e adultos falantes do PB mostram-se relevantes para que se verifique se esta restrição se apresenta uma vez que o clítico seja incorporado como possível opção, por intermédio do contato com a língua escrita e oral formal.

Este artigo se organiza da seguinte forma. Na seção 2, apresenta-se um contraste entre o PB e o PE, no que concerne às formas por meio das quais o OC é preferencialmente codificado, em função de fatores sintáticos e semânticos. Na seção 3, são apresentados e discutidos os resultados obtidos em duas tarefas de produção eliciada, em diferentes contextos sintáticos - sentenças simples e subordinadas causais, em que o fator animacidade foi manipulado. A primeira, com crianças/adolescentes de 4 - 15 anos, a segunda com crianças/adolescentes e adultos. Na seção 3, trazemos as considerações finais.

\section{POSSÍVEIS REALIZAÇÕES DO OC EM PB EM CONTRASTE COM PE}

Nos exemplos a seguir, vemos as possibilidades de realização do objeto correferencial, em PB:

(1) Joãoi saiu de casa cedo. A Ana viu ele entrando no elevador. ${ }^{2}$

(2) Joãoi saiu de casa cedo. A Ana oi viu entrando no elevador.

(3) João viu seu ônibusi parado no ponto, mas não conseguiu pegar ec ${ }^{3}$ i a tempo.

(4) João viu seu amigo; parado na esquina, mas não conseguiu falar com ele. Não percebeu que o amigoi estava esperando um táxi.

2 A co-indexicação está sendo utilizada apenas como forma de identificação do antecedente do OC, sem que haja vinculação sintática entre os elementos assim relacionados.

3 ec = empty category. 
Em (1), o pronome tônico recupera, em posição de objeto, um antecedente mencionado fora da sentença. Essa é uma forma bastante produtiva em PB falado, embora seja ainda fortemente estigmatizada em situações formais e na escrita monitorada. Em PE, esse uso do pronome tônico pode ser considerado agramatical.

Em (2), é o clítico acusativo o que recupera um antecedente que está fora da sentença. Em PE, o uso do clítico é mais produtivo nesses contextos, ainda que, diferentemente do PB, em que a próclise é preferida. Em PE, fatores de ordem lexical e sintática podem determinar o uso da próclise ou da ênclise A diferenciação entre os contextos em que uma ou outra posição do clítico é preferida revelou-se um processo relativamente custoso na aquisição da linguagem (COSTA E LOBO, 2005, 2006, 2011, dentre outros). Em PB, o clítico acusativo, enclítico e de $3^{a}$ pessoa, representa o uso normativo, mas praticamente inexiste na língua falada, em geral, restringindo-se à língua escrita formal, por influência do PE, sem que haja, contudo, necessariamente domínio, por parte do falante/escritor de PB, das condições em que o clítico é assim posicionado naquela variedade (DUARTE, 2016; KATO, 2017).

Em (3), o objeto nulo recupera discursivamente o ônibus em contexto em que o clítico seria preferido, em PE. O objeto nulo é, como vimos, uma possibilidade presente nas duas variantes da língua, contudo com diferentes restrições. No PE, o nulo sofre pelo menos uma restrição sintática que não ocorre no PB: é legítimo em frases simples, mas não em contextos conhecidos como ilhas sintáticas, particularmente ilhas fortes (cf. AUGUSTO, 1998), como orações coordenadas, por exemplo. Graças a essa restrição, é descrito por Raposo (1986), Costa; Lobo (2005, 2006), dentre outros, como uma variável ligada a um tópico nulo. Esse tipo de restrição não parece ser operativa no PB, ainda que o status gramatical do objeto nulo na língua adulta não esteja consensualmente estabelecido ${ }^{4}$. Discute-se sua natureza como pro(GALVES, 2001; KATO, 1993, 2001), um epíteto nulo (HUANG, 1991), um vestígio, uma categoria mista (RAPOSO, 2004) ou uma estrutura semelhante à elipse de VP, a elipse de DP (CYRINO, 1994, 2006), ainda que possa ser tomado como uma variável (MAIA, 1997).

Em (4), o antecedente é recuperado pelo DP ramificado ou completo, sendo essa uma estratégia muitas vezes considerada estranha ou agramatical, particularmente em sentenças complexas (COSTA; GROLLA, 2017), uma vez que sofre a chamada penalidade do nome repetido (LEITÃO; RIBEIRO; MAIA, 2012). O OC codificado por meio de um DP definido completo tende a retomar um antecedente apresentado com traço [-definido] e/ou trazer alguma distinção semântica, como em relações de hiponímia/hiperonínia (João pegou uma

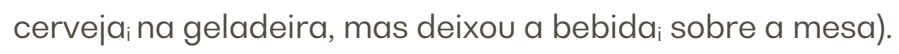

4 A motivação para as condições de ilha teve como propósito criar um contraste com o PE e verificar se há restrições a esse contexto em PB. 
Supõe-se que as crianças obedecem às restrições sintáticas que impedem formas pronominais de retomarem o sujeito da oração que as contém, mas não estão a par de todas as restrições semânticas/pragmáticas que permeiam o processo pelo qual uma dada forma é usada em relações de correferência (COSTA; GROLLA, 2017).

No momento da produção, o falante seleciona elementos do léxico que fazem interfaces com os sistemas de pensamento e os mantém na memória de trabalho para que a computação sintática se realize. Também mantém, na memória de trabalho, elementos já introduzidos no discurso, seja na sua fala ou na do interlocutor. O grau de recuperabilidade do antecedente de uma forma anafórica na memória de trabalho (isto é o seu grau de acessibilidade) pode influenciar a forma pela qual o OC se realiza. O traço de animacidade é apontado na literatura como um dos fatores que influenciam na recuperabilidade de um elemento no processamento linguístico (BOCK; WARREN, 1985).

A sensibilidade precoce por parte de crianças à animacidade como traço semântico relevante no estabelecimento de distinções gramaticais de gênero foi constatada em dados de compreensão, obtidos experimentalmente (CORRÊA; AUGUSTO; CASTRO, 2011). De acordo com Schwenter; Silva (2003), Schwenter (2006), dentre outros, no PB, os OCs tendem a ser nulos quando se referem a elementos inanimados/(+/-)específicos e animados/inespecíficos, e a ser plenos quando se referem a elementos animados específicos. Casagrande (2006), em estudo da fala longitudinal de uma criança crianças (1;8,12 - 3;7,6 anos) sustenta que a parte mais significativa dos seus dados corrobora essa tendência. Lopes e Castro (2005), por meio da observação de dados espontâneos de duas crianças (1,9 - 2,8 e 1,8 - 3,7 anos) também apontam que a animacidade do antecedente influencia na retomada, levando antecedentes inanimados a serem retomados por nulos e antecedentes animados a serem retomados por pronomes tônicos.

No PE, estudos recentes apontam restrições ao pronome tônico em posição acusativa (CARDINALETTI; STARKE,1999) e aumento na retomada com nulos com antecedentes inanimados (COSTA; FARIA; MATOS, 1998).

Há ainda fatores sociais e/ou pragmáticos que podem determinar a seleção de uma ou outra forma em diferentes contextos. O objeto nulo, por exemplo, muitas vezes é tomado como uma estratégia de esquiva ao uso estigmatizado do pronome tônico e ao uso preciosista do clítico (TARALLO, 1983); ou como recurso de uma gramática própria da linguagem oral prestigiada por meio de fatores puramente sociais: Calles (2006, p. 15), afirma que "na língua falada no dia a dia, predomina, especialmente no caso de falantes menos escolarizados, o emprego do ele acusativo no lugar do clítico". Duarte (2001, 2003), Bagno (2002), Freire (2000), Mattos; Silva (2004), dentre outros, afirmam, por outro lado, que o objeto nulo é a mais produtiva das estratégias de $\mathrm{OC}$ e praticamente não tem mais encontrado restrições de emprego no PB contemporâneo. 
Duarte (1989), por meio de dados da fala natural obtidos em entrevistas e gravações de linguagem de mídia, constatou que a retomada correferencial no PB com objeto nulo não causa estranhamento, "exceto àqueles que se situam num nível de escolaridade mais alto, a quem causam estranheza construções de que eles próprios fazem uso na fala natural" (DUARTE, 1989, p. 31, 32). Silva (2014), por meio da análise de 60 narrativas produzidas por 30 participantes dividos em três grupos de escolaridade (Ensino Fundamental, Médio e Superior) constatou que a escolaridade foi um fator determinante na seleção da forma correferencial; sendo o pronome lexical a forma preferida entre os alunos cursando o Ensino Fundamental (36,4\% nas narrativas orais e $14,8 \%$ nas narrativas escritas), enquanto o clítico acusativo foi a forma preferida entre os alunos do Ensino Superior (32,1\% tanto nas narrativas orais, quanto nas narrativas escritas). Pereira; Coelho (2013) encontraram resultados compatíveis com a hipótese de que, quanto maior o grau de escolaridade do participante, maior é uso do clítico, e quanto menor é o seu grau de escolaridade, maior é o uso do pronome tônico, na retomada correferencial. Em análise de corpus composto de redações produzidas por alunos do sexto ao nono ano do Ensino Fundamental de escolas públicas de Florianópolis, encontraram pronomes tônicos em percentuais mais altos (58\% e 76\%) entre os participantes com escolaridade menor, e mais clíticos acusativos (44\% e 41\%) entre os participantes com escolaridade maior.

Diante do exposto, dois experimentos foram conduzidos, a fim de verificar (i) o efeito da animacidade no uso de formas nulas/plenas; (ii) o uso de formas nulas em contexto de ilhas; (iii) se há efeito da idade/escolaridade no surgimento de clíticos.

\section{PRODUÇÃO ELICIADA DE OBJETO CORREFERENCIAL}

Com vistas a atender aos objetivos (i) e (iii), a produção do OC em sentenças simples foi eliciada por meio de uma pergunta QU, precedida por uma introdução, que visava a criar um pequeno contexto discursivo. Para o objetivo (ii), assim como em atenção ao (iii), um pequeno contexto prévio também foi criado, porém seguido de uma sentença complexa a ser completada pelo participante, em tarefa do tipo cloze ${ }^{5}$, na qual o participante deve completar a sentença enunciada pelo experimentador. As duas tarefas foram conduzidas em uma mesma sessão experimental. Para ambas as tarefas, as variáveis independentes

\footnotetext{
5 A técnica de cloze foi criada com o propósito de monitorar e avaliar a compreensão de leitura. Um pequeno texto é apresentado com a omissão de algumas palavras para que essas lacunas sejam preenchidas pelo leitor, de forma coerente com o texto cuja leitura se encontra em processo. Como extensão dessa técnica, em experimentos de produção eliciada, apresenta-se uma sentença para ser completada pelo participante, de acordo com a informação previamente dada.
} 
foram animacidade (fator intra-sujeitos) e idade/escolaridade (fator grupal), sendo que, para o grupo de adultos, na Tarefa 2 , foi adicionada a variável modalidade da língua (oral e escrita, também um fator grupal). As seguintes condições experimentais foram definidas em função de animacidade em cada tarefa:

\section{Tarefa 1 (perguntas QU)}

- Antecedente [- animado]: Aqui tem um menino e uma televisão. E agora? O que o menino está fazendo com a televisão?

- Antecedente [+animado]: Aqui tem um macaco e um gato. E agora? O que o macaco está fazendo com o gato?

\section{Tarefa 2 (cloze)}

- Antecedente [- animado]: Aqui tem um gato e um copo de leite. Agora veja o que está acontecendo! O gato está bebendo o leite do copo. Então, o leite vai acabar porque o gato...

- Antecedente [+animado]. Ex: Aqui tem uma menina e uma bailarina. Agora veja o que está acontecendo! A menina está enfeitando a bailarina. Então, a bailarina vai ficar bonita porque a menina...

O número de ocorrências de cada possível forma de OC foi tomado como variável dependente. Com base em dados da produção espontânea, foi esperado que o objeto nulo fosse a forma privilegiada para retomada de antecedentes [-animados], enquanto antecedentes [+animados] favoreceriam o pronome tônico. A idade afetaria a produção do clítico, que apareceria somente após a escolarização, na produção de adolescentes e de adultos. Quanto ao DP pleno, não foram feitas previsões específicas. Sua presença pode ser indicativa da necessidade de recompor todos os traços do antecedente, em um discurso menos concatenado com a fala do interlocutor, o que pode prevalecer nos grupos mais jovens. Pode também servir como estratégia de esquiva ao uso do pronome tônico, como efeito de escolarização, em contextos em que o clítico seria esperado na escrita ou na fala formal.

\section{MÉTODO}

Participaram 108 crianças falantes de PB, oriundas das escolas públicas do Rio de Janeiro (54 do sexo femino, sem disfunções cognitivas/de linguagem), divididas em 3 grupos (36 participantes, cada): (i) idade pré-escolar/alfabetização (4,3 - 7,11 anos; idade média: 5,7; 18 participantes do sexo feminino); (ii) $1^{\circ}$ segmento (8,6 - 11 anos; idade média: 9,8; 17 participantes do sexo feminino) e (iii) $2^{\circ}$ segmento (12,6 - 15,1 anos; idade média: 13,9; 21 
participantes do sexo feminino) do Ensino Fundamental (ES). Como as idades dos participantes variavam entre quatro e quinze anos, seria possível observar desde o final do período de aquisição da língua até o fim do ES, quando o conhecimento da modalidade escrita da língua, estaria, em princípio, consolidado, possiblitando verificar se a aprendizagem escolar propiciaria a escolha de formas que não são adquiridas naturalmente pela criança.

Adicionalmente, um grupo de adultos foi tomado como referência para o conhecimento-alvo da língua. Este foi composto por 20 adultos falantes nativos de PB, com idades entre 31 e 57 anos (idade média: 44 anos), servidores públicos (12 do sexo feminino), com nível de escolaridade superior.

O material para cada teste consistiu de quatro estímulos para um pré-teste, dois introduzindo cada tipo de tarefa e doze estímulos experimentais, seis por contdição experimental, para cada tarefa. A sequência de frases que compunha cada condição experimental foi apresentada junto a um par de imagens, no qual a primeira apresentava os antecedentes e a segunda, o evento a ser descrito pela criança.

Foram elaboradas quatro listas, contendo as quatro sequências de frases que compunham o pré-teste, juntamente com as 24 de frases experimentais (seis para cada condição), semi-aleatorizadas. Desse modo a sequência dos estímulos experimentais nunca foi a mesma, bem como a mesma condição não foi apresentada mais de uma vez, consecutivamente.

Assim, cada evento ( trial) foi apresentado como no exemplo que se segue:
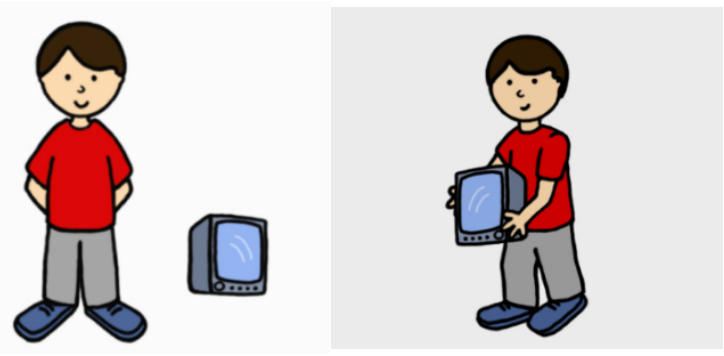

Figura $1 .{ }^{6}$ Conjunto pertencente à Tarefa 1.

As frases experimentais correspondentes às imagens foram: "Aqui tem um menino e uma televisão. / E agora? O que o menino está fazendo com a televisão?”.

Nas frases experimentais, a sentença inicial era a existencial "Aqui tem $\mathrm{X}$ e $\mathrm{Y}$ ", que criava um contexto prévio, no qual os antecedentes críticos, com traço [+/- animado] eram os complementos. Após essa sentença inicial, uma chamada tal como "E agora?" ou "Agora veja o que está acontecendo!", lograva chamar a atenção da criança para o que seria dito.

6 As imagens utilizadas nas tarefas são do acervo de imagens do LAPAL, originalmente criadas para o MABILIN (Módulos de Avaliação de Habilidades Linguísticas; CORRÊA, 2000). 
Por último induzia-se a produção de alguma forma correferencial com caso acusativo: na Tarefa 1, a criança respondia à pergunta QU-: “O que X está fazendo com Y?” Na Tarefa 2, a criança era levada a produzir um objeto direto em uma oração subordinada causal, isto é, uma ilha sintática, como em: "Agora Y vai [verbo + predicativo] porque X..."

Nos condições experimentais foram contrabalançados o gênero e o número do antecedente, assim como a posição (à esquerda ou à direita) na sentença e no slide, nos quais o antecedente crítico foi apresentado.

O aparato consistiu de um notebook MacBook Air 13", 2014, versão 10.12.6 e aplicativo gravador de áudio, Audio Recorder, versão 2.00.35, instalado num aparelho de telefone ceIular Sony Xperia X, versão Android 8.0.0.

As crianças e adolescentes foram testados individualmente por dois experimentadores (um por participante), em uma sala isolada da escola, reservada para esse fim. Eles foram convidados a participar de um jogo no computador, no qual viam imagens em slides. $\mathrm{O}$ experimentador apresentava primeiro os slides e frases do pré-teste, e apenas as crianças que demonstrassem entender a atividade continuavam a fazê-la (duas crianças não prosseguiram para as tarefas experimentais). Cada um levov em média cinco minutos para concluir todo o período experimental.

Já com os adultos, o material foi apresentado oralmente (a 10 participantes), do mesmo modo como foi feito com as crianças; e por escrito (a 10 participantes).

Os dados obtidos em cada tarefa foram analisados separadamente. Para cada variável dependente foi conduzida uma ANOVA com design 2 (animacidade) $\times 3$ (idade) (o primeiro within-subject). Os dados obtidos com adultos na Tarefa 2 foram analisados de forma independente, incluindo-se modalidade como fator grupal

\section{TAREFA 1}

O Gráfico 1 apresenta a distribuição das respostas para cada tipo de forma correferencial possível na posição de objeto. Observa-se a preferência pelo objeto nulo e pelo DP pleno, seguida do pronome tônico. Apresentam-se, a seguir, os resultados obtidos com cada uma dessas formas, exceto os clíticos que apresentam baixíssima frequência nessa tarefa (duas ocorrências). 


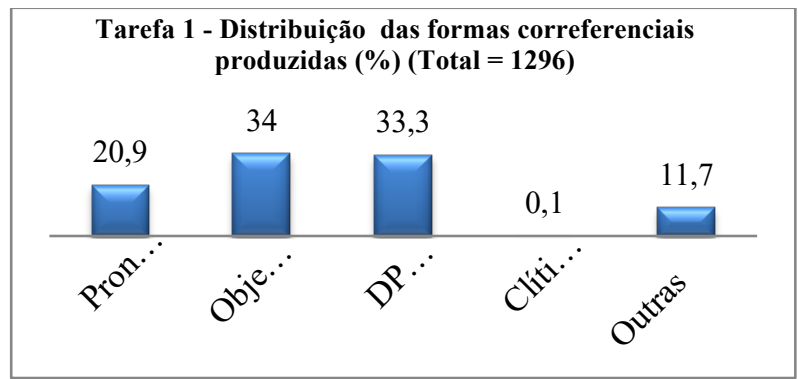

Gráfico 1

Para o pronome tônico, houve um efeito principal significativo de animacidade $(F(1,105)$ = 92,8 p<0,0001 SS=100,04 MSe=1,080 Médias: Inanimados = 0,57, Animados = 1,94) (Cf. Gráfico 2); e de idade $(F(2,105)$ = 3,17 p<0,05 SS=12,40 MSe=1,95 Médias: Grupo I = 1,4, Grupo II = 1,4, Grupo III = 0,9), com médias apresentadas no Gráfico 3. Observa-se a preferência por essa forma com antecedente [+animado], assim como o decréscimo em seu uso no grupo de adolescentes.

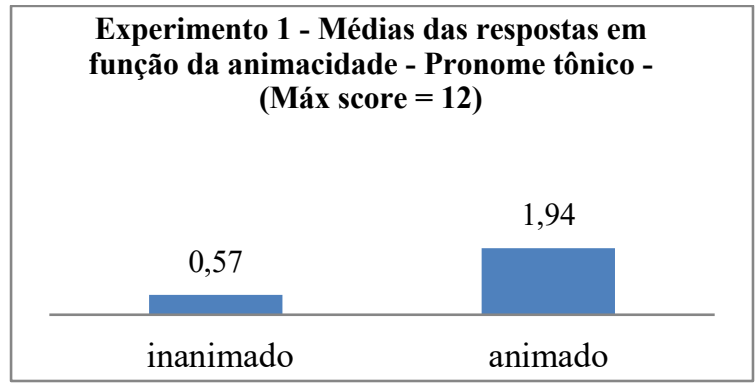

Gráfico 2.

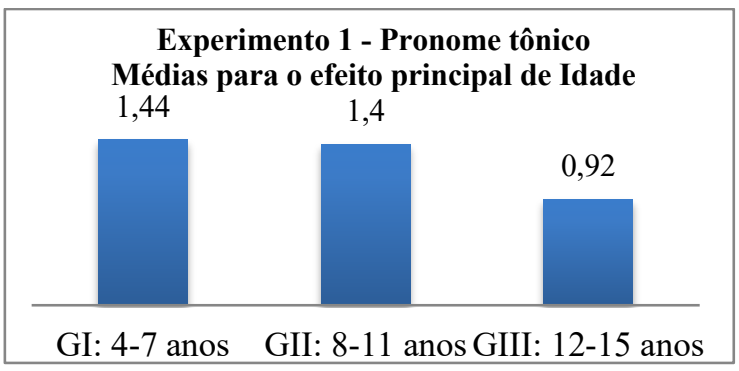

Gráfico 3.

Tomando-se o objeto nulo, houve efeito principal significativo de animacidade $(\mathrm{F}(1,105)$ = 90,7 p<0,00001 SS=121,50 MSe=1,34 Médias: Inanimados = 2,78, Animados = 1,29), conforme apresentado no Gráfico 4; e da interação animacidade vs idade $(F(2,105)=7,01 p<0,01$ SS=18,78 MSe=1,34 Médias: Grupo I = Inanimados = 2,94, Animados = 1,44, Grupo II = Inanimados = 2,97, Animados = 0,75, Grupo III = Inanimados =2,44, Animados =1,67), como se vê no Gráfico 5. Como previsto, essa forma é preferencialmente utilizada com antecedentes 
[-animados], embora haja uma queda de seu uso com antecedentes [+animados] no grupo de 8 a 11 anos, mantendo-se estável a frequência nas demais condições.

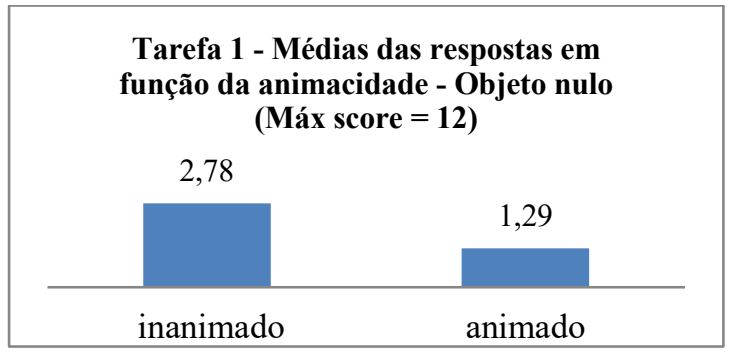

Gráfico 4.

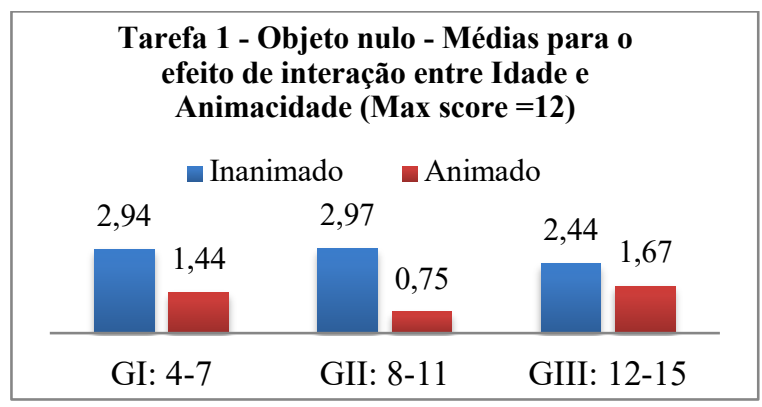

Gráfico 5

Para o DP pleno, também houve efeito principal significativo de animacidade $(F(1,105)=46,0 p<0,0001$ SS=60,17 MSe=1,31 Médias: Inanimados =2,53, Animados = 1,47; (cf. Gráfico 6), além da interação entre animacidade e idade $(F(2,105)=3,96 p=0,02$ SS=10,36 MSe=1,31; Médias: Grupo I - Inanimado = 2,19; Animado = 1,25; Grupo II - Inanimado = 2,22; Animado = 1,64; Grupo III - Inanimado = 3,17; Animado = 1,53) (cf. Gráfico 7). Constata-se um aumento no uso da forma plena em função de idade, sendo que este se dá entre os grupos I e II. no que concerne aos antecedentes animados, e entre os grupos II e III, no que diz respeito aos inanimados.

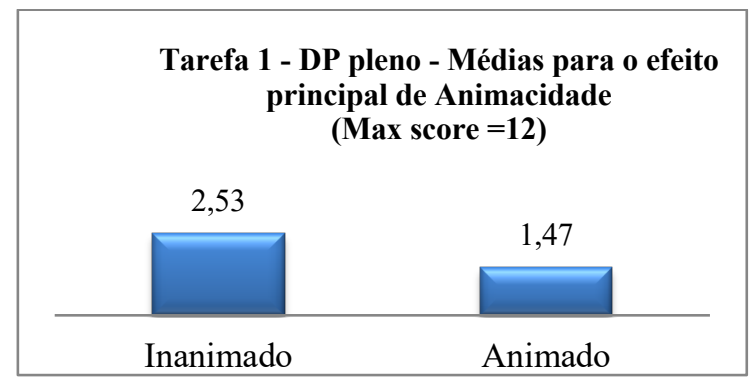

Gráfico 6. 


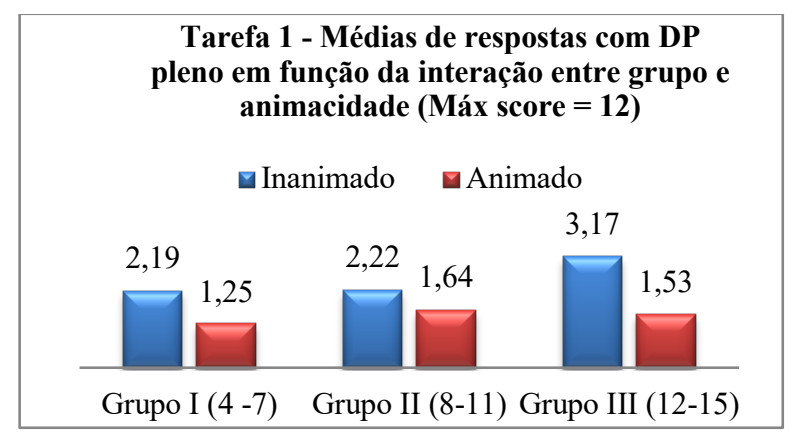

Gráfico 7.

\section{TAREFA 2}

O Gráfico 8 apresenta a distribuição das respostas para cada tipo de forma correferencial possível na posição de objeto complemento em oração causal. Nesse contexto, diferentemente da sentença simples, da Tarefa 1, observa-se a predominância do pronome tônico, seguida do objeto nulo, uma baixa frequência de DPs plenos, e uma presença de clíticos que, embora pouco expressiva, é consideravelmente maior (total de 21 respostas) do que na Tarefa 1. Apresentam-se, a seguir, os resultados para as primeiras três formas.

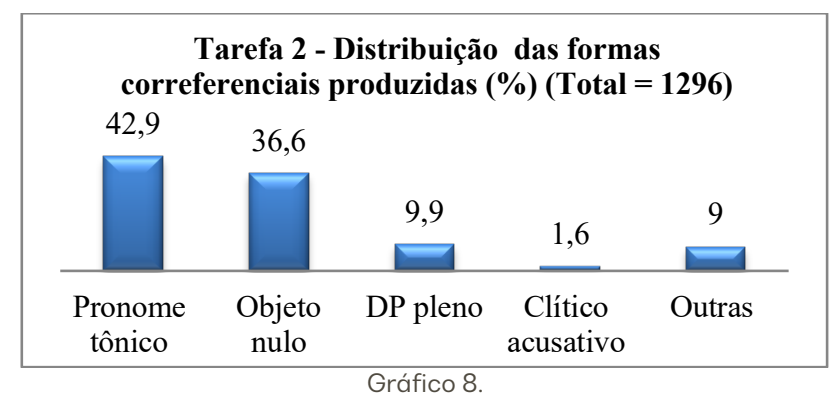

Tanto para o pronome tônico quanto para o objeto nulo, houve um efeito principal significativo de animacidade, em direção contrária: $(F(1,105)=179$ p<0,0001 SS=275,63 $\mathrm{MSe}=1,54$ Médias: Animado = 3,70; Inanimado = 1,44), para o pronome tônico (cf. Gráfico 9) e $(F(1,105)=247$ p<0,000001 SS=389,35 MSe=1,57 Médias: Inanimado = 3,53; Animado = 0,85), para o objeto nulo (cf. Gráfico 10). Nota-se que a preferência pelo pronome tônico com antecedentes animados e do nulo com inanimados mostra-se mais expressiva nesse contexto sintático (oração subordinada causal) do que em sentenças simples, o que sugere que o efeito do traço em questão se faz mais presente no âmbito do período complexo. Para ambas as variáveis, os demais efeitos não foram significativos. 


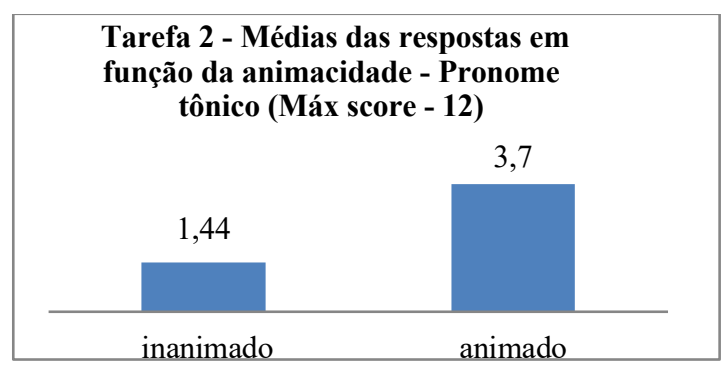

Gráfico 9.

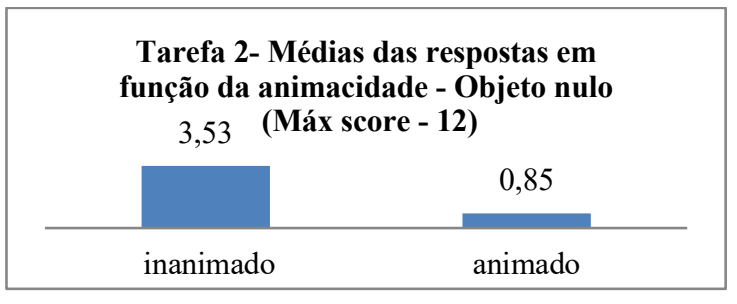

Gráfico 10

Também nesse contexto, houve um efeito principal significativo de animacidade quando o DP pleno é analisado: $(F(1,105)=15,8$ p <0,001 SS=13,00 MSe=0,82 Médias: Animado $=1,47$; Inanimado = 0,84) (cf. Gráfico 11) e de idade $(F(2,105)=5,16$ p<0,01 SS=16,69 MSe=1,62 (Médias: Grupo I = 0,94; Grupo II = 0,26; Grupo III = 0,58) (cf. Gráfico 12). Consta-se que a forma plena é usada preferencialmente com antecedentes animados e que seu uso é maior no grupo de crianças mais novas (pré-escolares) e no grupo de adolescentes, o que pode ser atribuído a diferentes razões, como será discutido adiante.

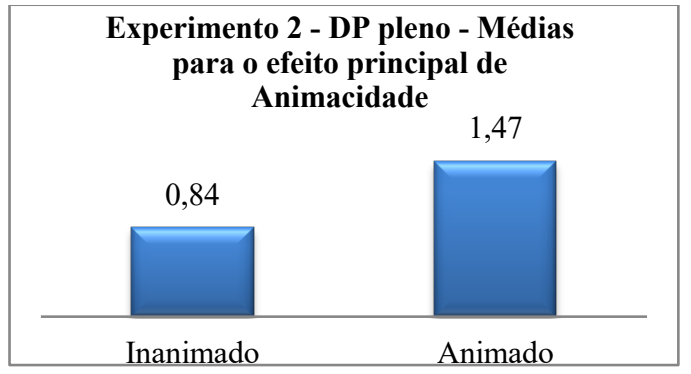

Gráfico 11.

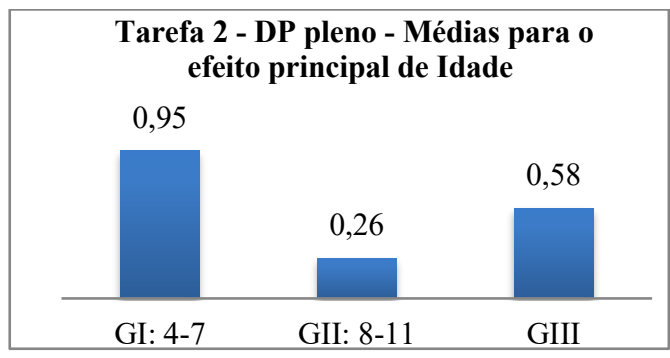

Gráfico 12. 
Quanto aos clíticos, houve 11 ocorrências no Grupo II e 10 no grupo III, como possível consequência de escolaridade, como previsto. Tomando-se o total dessas respostas, constata-se que 57,1\% ocorreram com antecedentes inananimados e 42,9\% com animados, o que, ainda que não caracterize uma preferência, pode sugerir uma estratégia de esquiva ao nulo nesse contexto.

Para os adultos, a distribuição das respostas para cada forma correferencial possível está apresentada nos Gráficos 13 (modalidade oral) e 14 (modalidade escrita). Observa-se que na modalidade oral, a forma tônica e o DP completo predominam. A presença do clítico é pouco frequente, embora considerávelmente maior do que o que foi observado no grupo de adolescentes. Na modalidade escrita, contudo, a forma preferencial é o clítico, sendo a forma nula a de menor frequência.

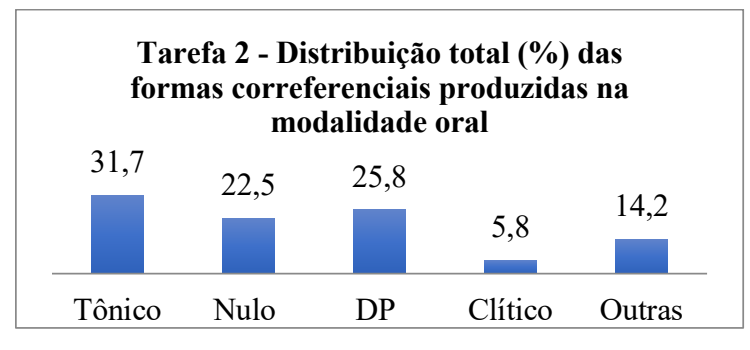

Gráfico 13.

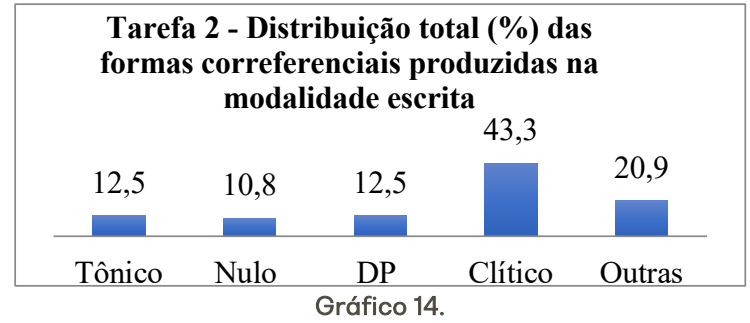

Tomando o pronome tônico como variável dependente, ainda que a frequência desta forma tenha sido baixa, houve um efeito principal significativo de animacidade $(F(1,18)=11,2$ p<0,01 SS=7,23 MSe=0,65; Médias: Inanimado = 0,9; Animado = 1,75 (cf. Gráfico 15) e da interação entre animacidade e modalidade $(F(1,18)=8,69 \mathrm{p}<0,01 \mathrm{SS}=5,62 \mathrm{MSe}=0,65$; Médias: Oral - Inanimado = 1,1; Animado = 2,7; Escrito: Inanimado = 0,7; Animado = 0,8 (cf. Gráfico 16). 


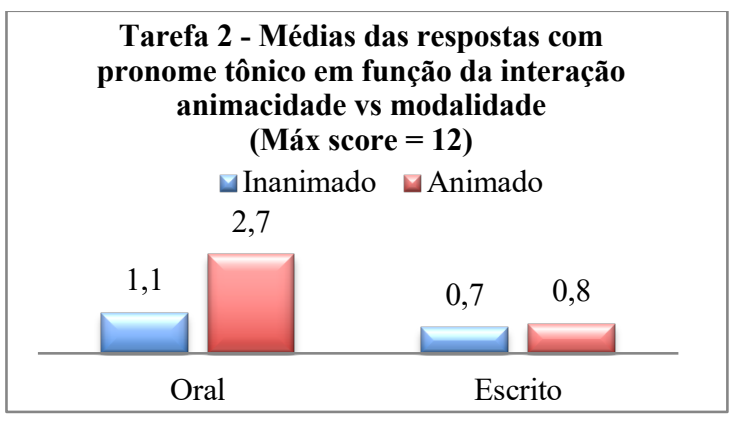

Gráfico 15.

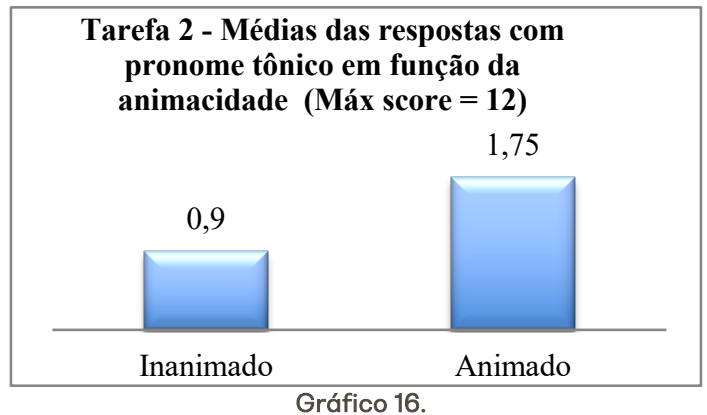

Observa-se que a preferência para essa forma com antecedente animado se deu na modalidade oral, dado a quase total inexistência de ocorrências desssa forma na modalidade escrita. Não houve efeitos significativos para o objeto nulo.

Para o DP pleno, um efeito principal significativo de animacidade também foi obtido $(F(1,18)=45,5$ p<0,00001 SS=14,40 MSe=0,32; Médias: Inanimado = 1,75; Animacidade = 0,55 (cf. Gráfico 17), tal como o da interação modalidade vs animacidade $(F(1,18)=15,5$ $\mathrm{p}<0,001 \mathrm{SS}=4,90 \mathrm{MSe}=0,32$; Médias: Oral - Inanimado = 2,5; Animado = 0,6; Escrito - Inanimado $=1 ;$ Animado $=0,5$ (cf. Gráfico 18). Este efeito revela que a preferência pelo antecedente [-animado] se manifesta particularmente na modalidade oral.

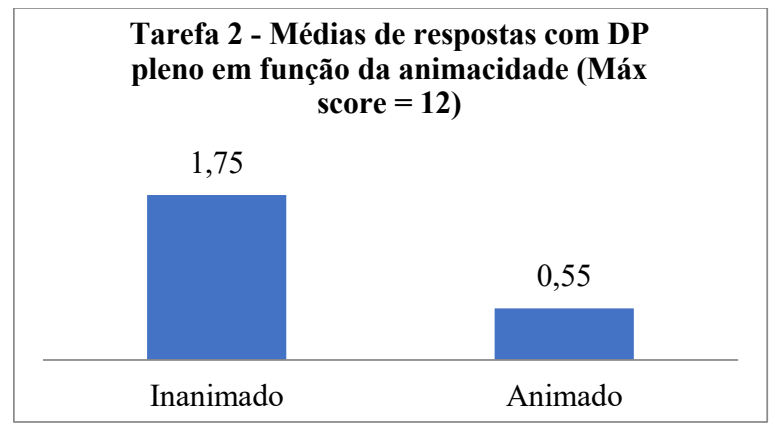

Gráfico 17. 


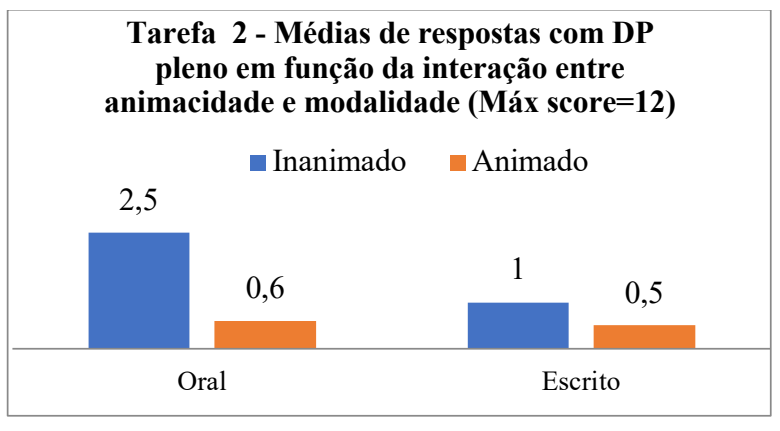

Gráfico 18.

Para o clítico, houve efeito principal significativo de modalidade $(F(1,18)=7,02$ p<0,02 SS=50,62 MSe=7,21; Médias: Oral = 0,35; Escrito = 2,6), como seria esperado (cf. Gráfico 19). Não houve efeito significativo de animacidade e nem de interação entre animacidade e modalidade.

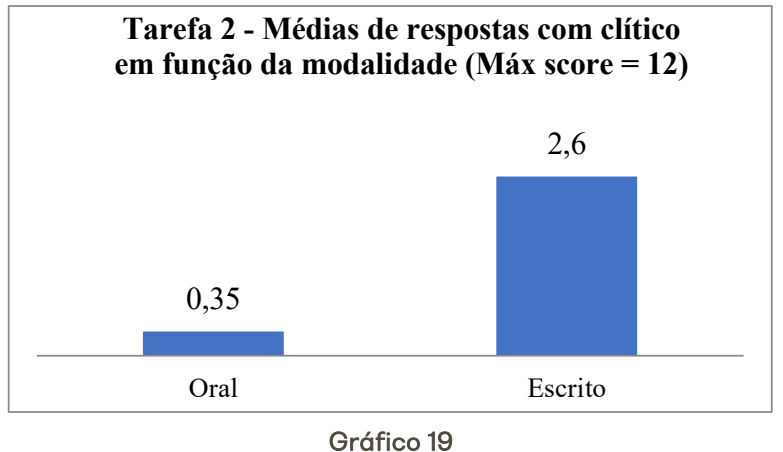

\section{DISCUSSÃO}

Os resultados relativos ao efeito de animacidade são compatíveis com o que tem sido observado em dados da fala espontânea de crianças e na literatura linguística referente ao PB. A preferência pelo pronome tônico com antecedentes [+animados] e do objeto nulo com [-animados] foi, não obstante, mais expressiva na Tarefa 2, em que o OC ocorre em oração causal, possívelmente devido à maior acessibilidade do antecedente nesse contexto. A produção do OC em sentenças simples em resposta à pergunta QU (Tarefa 1) favoreceru o uso do DP completo. Nessa tarefa, o objeto nulo e o DP completo competem, com certa vantagem para o nulo. A presença de DPs com antecedentes inanimados nos grupo mais jovem pode sinalizar relativa dificuldade na concatenação da sentença simples produzida com a fala do interlocutor.

Também de acordo com o previsto para o PB, o número de clíticos foi praticamente inexistente na fala de crianças/adolescentes, havendo, contudo algumas ocorrências em 
consequência de escolarização, particularmente na Tarefa 2, ou seja, no contexto de ilha, no qual há restrições ao objeto nulo e prevalência do clítico no PE. Ainda que não haja restrições ao objeto nulo nesse contexto no PB, a presença relativamente maior do clítico na Tarefa 2, particularmente com antecedentes inanimados, que em geral favorecem o uso do objeto nulo, pode sinalizar a influência das restrições que se aplicam àquela variedade. Essa influência mostra-se presente no grupo de adultos, em que o clítico prevalece na língua escrita, independementente de animacidade.

A maior incidência de objetos nulos com antecedentes animados nos grupos de maior grau de escolarização, como observado na Tarefa 1, talvez indique que, em decorrência desta, o uso do pronome tônico em posição acusativa mostre-se um pouco estranho para a criança. Uma vez que o clítico não se mostra produtivo na língua oral, como tem sido apontado (SCHWENTER; SILVA. 2003; SCHWENTER, 2006), a criança/adolescente parece recorrer ao nulo. O efeito de escolarização pode ainda justificar a ocorrência de DPs plenos, a qual se torna mais expressiva entre as crianças mais velhas, possivelmente como estratégia de esquiva ao uso do pronome tônico, já percebido como estigmatizado em alguns contextos. A situação experimental pode ser percebida como um contexto pouco informal para esses particpantes. Observa-se, por outro lado, que o condicionamento social também pode contribuir para as taxas reduzidas do clítico na produção oral de adolescente e adultos, dada a formalidade que seu uso sugere.

\section{CONSIDERAÇÕES FINAIS}

De forma consistente com a literatura e com as previções iniciais, nas duas tarefas, as crianças se mostraram sensíveis ao traço de animacidade do antecedente, desde as faixas etárias mais jovens analisadas. Animacidade favorece o uso de pronomes tônicos quando o referente é animado e de objetos nulos (ou DPs plenos) quando o referente é inanimado. Os resultados obtidos em contexto de ilha sintática são, por um lado, compatíveis com a hipótese de que a natureza gramatical do objeto nulo em PB o distingue do PE. Enquanto as restrições ao objeto nulo no PE sugiram que se trata de uma variável ligada ao tópico (RAPOSO, 1986), sua ocorrência em contexto de ilha no PB é compatível com sua análise como pro (GALVES, 2001; KATO, 1993, 2001) ou como elipse de DP(CYRINO, 1994; 2016). Por outro lado, o objeto nulo no PB pode assumir uma natureza distinta mediante a escolarização, quando o clítico passa ser incorporado, dado que se observa, no grupo de crianças mais velhas e adolescentes, uma possível tendência a um uso preferencial dessa forma com antecedentes inanimados, que favoreceriam o nulo, assim como a prevalência de promomes tônicos e DPs completos na produção oral de adultos. É interessante observar, no que diz respeito ao objeto nulo, que crianças de tenra idade falantes de PE apresentam 
altas taxas dessa forma em contexto de ilha. É possível, portanto, que restrições desse tipo sejam de algum modo decorrentes ou intensificadas pela escolarização em ambas as variedades, ainda que de forma diferenciada.

Uma análise contrastiva com falantes de PE (em andamento) poderá revelar em que medida as variáveis aqui manipuladas afetam o processo de aquisição de cada variedade do portuguès e medidas on-line em experimentos com adultos podem ser mais informativas quanto ao status do objeto nulo e ao papel da escolarização no uso dessa forma.

\section{REFERÊNCIAS}

BOCK, J. K.; WARREN, R. Conceptual accessibility and syntactic structure in sentence formulation. Cognition, 21,1985 , p. 47-67

CALLES, D. C. Considerações sobre estratégias alternativas ao clítico de terceira pessoa na representação do acusativo anafórico. Revista Letra Magna. Revista Eletrônica de Divulgação Científica em Língua Portuguesa, Lingüística e Literatura, ano 3, n. 4, 2006.

CARDINALETTI, A.; STARKE, M. The tipology of structural deficiency: a case study of the three classes of pronouns. In: VAN RIEMSDIJK, H. (Ed.) Clitics in the languages of Europe, 1985. p. 145-234.

CASAGRANDE, S. A aquisição de clíticos acusativos e o objeto nulo no PB. Revista de Estudos Linguísticos, Belo Horizonte, v. 14, n. 2, p. 341-370, jun./dez. 2006.

CASAGRANDE, S.; ROSSI, J. C. O objeto direto anafórico em português brasileiro: comparação entre dados de aquisição e de aprendizagem. Revista de Estudos Acadêmicos de Letras, v. 11, n. 01, p. 47-62, 2018.

CHOMSKY, N. Lectures on Government and Binding. Dordrecht: Foris, 1981.

CORRÊA, L. M.; AUGUSTO, M. R. A.; CASTRO, A. Agreement and markedness in the ascription of gender to novel animate nouns by children acquiring Portuguese. Journal of Portuguese Linguistics, 9-2 (2010)/10-1 (2011), p. 121-142.

COSTA, M. A.; FARIA, I. H.; MATOS, G. Ambiguidade referencial na identicação do sujeito em estruturas coordenadas. Actas do XII Encontro Nacional da Associação Portuguesa de Linguística, 1998. p. 173-188.

COSTA, J.; GROLLA, E. Pronomes, clíticos e objetos nulos: dados de produção e compreensão. In: FREITAS, M. J.; SANTOS, A. L. (eds.). Aquisição de língua materna e não materna: questões gerais e dados do português. Berlin: Language Science Press, 2017. p. 177-199.

COSTA, J.; LOBO, M. A aquisição de clíticos em PE: omissão de clíticos ou objectos nulos? In: XXI Encontro Nacional da APL. Textos seleccionados. Lisboa: APL, 2006. p. 285-293.

COSTA, J.; LOBO, M. Objeto nulo na aquisição do português europeu: pro ou variável? Textos Selecionados. XXVI Encontro da Associação Portuguesa de Linguística. Lisboa, APL: 2011. pp. 197 - 207.

COSTA, J.; LOBO, M. Clitic Omission, null objects or both in the acquisition of European Portuguese? In: Sergio Baauw; Frank Drijkonongen; Manuela Pinto (eds.). Romance Languages and Linguistic Theory. Amsterdam, Philadelphia: John Benjamins, 2005. p. 59-72.

CYRINO, S. M. L. (1994). O objeto nulo no português do Brasil: um estudo sintático-diacrônico. Tese de doutorado, UNICAMP, Campinas (Publicada em 1997 pela Ed. da Universidade Estadual de Londrina, Londrina PR.).

CYRINO, S. M. L. Algumas questões sobre a elipse de VP e o objeto nulo em PB e PE. In: GUEDES, M.; BERLINK, R. de A.; MURAKAWA, C. de A. A. (Orgs.) Teoria e análise linguísticas: novas trilhas. Araraquara: Laboratório Editorial FCL/UNESP, SP, Cultura Acadêmica, 2006. p. 53-79. 
DUARTE, I.; MATOS, G.; GOÇALVES, A. Pronominal clitics in European and Brazilian Portuguese. Journal of portuguese linguistic, 4, (2), 2005. p. 112-141.

DUARTE, M. E. L. Clítico acusativo, pronome lexical e categoria vazia no português do Brasil. In: TARALLO, Fernando. (Org.). Fotografias Sociolinguísticas. Campinas, SP: Pontes: Editora da UNICAMP, 1989.

DUARTE, M. E. L. Ensino da língua em contexto de mudança. In: Cadernos do IV Congresso Nacional de Lingüística e Filologia. Vol. IV, n. 12, Rio de Janeiro: 2001.

DUARTE, M. E. L. Para uma nova descrição da sintaxe do 'Português padrão'. Cadernos de Letras da UFF Dossiê: Variação linguística e práticas pedagógicas, 51, 2016. p. 23-41.

FREIRE, G. C. Os clíticos de terceira pessoa e as estratégias para sua substituição na fala culta brasileira e lusitana. Dissertação de mestrado. Rio de Janeiro, UFRJ, 2000.

GALVES, C. M. C. Ensaios sobre as Gramáticas do Português. Campinas, SP: Ed. da Unicamp, 2001.

HUANG, C. T. J. Remarks on the Status of the Null Object. In: Freiden, R. (Ed). Principles and Parameters in Comparative Grammar. Cambridge, Massachusetts: MIT Press, 1991. p. 56-76.

KATO, M. A variação no domínio dos clíticos no português brasileiro. Linguística, v.33, n.1, Montevideo, Jun. 2017.

KATO, M. A. The Distribution of Pronouns and Null Elements in Object Position in Brazilian Portuguese. In: ASHBY, W., PERISSINOTTO, M. M. G.; RAPOSO, E. (Orgs.) Linguistic Perspectives on the Romance Languages, Amesterdam, John Benjamins, 1993.

KATO, M. A.; MARTINS, A. M. European Portuguese and Brazilian Portuguese: an overview on word order. In: WETZELS, L., MENUZZI, S. \& COSTA, J. (Eds.), The Handbook of Portuguese Linguistics. Hoboken, NJ: WileyBlackwell, 2016.p.15-40.

LEITÃO, M.M; RIBEIRO, A. J. C.; MAIA, M. Penalidade do nome repetido e rastreamento ocular em português brasileiro. Revista LinguíStica / Revista do Programa de Pós-Graduação em Linguística da Universidade Federal do Rio de Janeiro, v. 8, n. 2, 2012.

LOPES, R. E. V. The production of subject and object in Brazilian Portuguese by a young child. Probus (Dordrecht), Berlin, v. 15, n.1, p. 121-144, 2003.

LOPES, R. E. V.; QUADROS, R. M. Traços semânticos na aquisição da linguagem: há efeitos de modalidade de língua? Revista da ABRALIN, Belo Horizonte, v. 4, n.1/2, p. 75-108, 2005.

MAIA, M. A. R.. The Processing of Object Anaphora in Brazilian Portuguese. Revue Linguistique de Vincennes, França, (26), , 1997. p. 151-176.

MATTOS E SILVA, R. V. O português são dois: novas fronteiras, velhos problemas. São Paulo: Parábola, 2004.

NUNES, J. M. Direção de cliticização, objeto nulo e pronome tônico na posição de objeto em português brasileiro. In: KATO, M. A. e ROBERTS, I. (orgs.) Português brasileiro: uma viagem diacrônica. 2 ed. São Paulo: Editora da UNICAMP, 1996. p. 207-222.

NUNES, J. De clítico à concordância: o caso dos acusativos de terceira pessoa em português brasileiro. Cadernos de Estudos Linguísticos. 57.1. Campinas, Jan./Jun. 2015.

PAGOTTO, E. Clíticos: mudança e seleção natural. In: KATO, M. A. e ROBERTS, I. (orgs.) Português brasileiro: uma viagem diacrônica. 2 ed. São Paulo: Editora da UNICAMP, 1996. p. 185-206.

PEREIRA, I.; COELHO, I. L. O uso variável das formas anafóricas no acusativo. Letrônica, Porto Alegre, v. 6, n. 1, p. 288-318, jan./jun., 2013. Disponível em:

http://revistaseletronicas.pucrs.br/ojs/index.php/letronica/article/view/13422. Acesso em: 24 abr. 2020

TARALLO, F. L. Relativization strategies in Brazilian Portuguese. Tese de Doutorado. Univ. of Pennsylvania.USA, 1983.

RAPOSO, Eduardo P. On the null object in european portuguese. In: JAEGGLI, O.; SILVA-CORVALÁN, C. (Ed.). Studies in Romance Linguistics. Foris, Dordrecht, 1986. p. 373-390. 
RAPOSO, E. P. Colocação dos clíticos nas línguas românicas: aspectos universais e aspectos particulares. USCB, 2004.

SILVA F.B. A realização do objeto direto anafórico por clíticos e pronomes lexicais: um caso de variação. CLARABOIA: Revista do Curso de Letras da UENP, Jacarezinho-PR, n. 1/2, p. 57-74, jun./dez. 2014.

SCHWENTER, S. A. Null Objects across South America. Selected Proceedings of the 8th Hispanic Linguistics Symposium, ed. Timothy L. Face and Carol A. Klee, 23-36. Somerville, MA: Cascadilla Proceedings Project, 2006.

SCHWENTER, S. A.; SILVA, G. Anaphoric Direct Objects in Spoken Brazilian Portuguese: Semantics and Pragmatics. Revista Internacional de Linguística lberoamericana, v. 1, n. 2, out. 2003. p. 99-123. 